the regulations for higher degree courses, leading to the M.A., M.Sc., Ph.D. and M.Phil. degrees. The first full-time postgraduate course, for an M.Sc. in Applied Solid State Physics at Brighton College of Technology, has been approved, and others are in the pipeline. The Council has also set up several new subject boards as well as a committee to consider proposals for degree courses in education from colleges of education and technical colleges. It has also adopted its own academic dress, and opens its report with a drawing of its armorial bearings. It is beginning to look like an established institution.

The Council has clearly been thinking deeply about the White Paper setting out the plan for polytechnics and other colleges, but the new report says little about this. It is content to record the assumption that the polytechnics will get the staff, accommodation and equipment they need, and its concern that the polytechnic policy of concentrating resources will not prejudice students following C.N.A.A. courses. The Council has obviously been greatly encouraged by the recommendation of the Committee of Vice-Chancellors and Principals, which recommended that universities should regard holders of C.N.A.A. degrees on the same footing as holders of university degrees.

\section{More from Medlars}

THE United States Library of Medicine has stored on magnetic tape the vast quantity of information which is used each year to produce the Index Medicus and has for some months been disseminating this information through the Medical Literature Analysis and Retrieval System (MEDLARS). One way in which this can be done is in the form of specialist biblio. graphies covering topics of interest to individuals or groups of research workers, and this service has now become available to British scientists through the National Lending Library.

The bibliographies are of three kinds. Some are firmly established, such as the Index of Rheumatology and the Index to Dental Literature; these are published regularly by the National Library of Medicine and cost money. Others are still at an experimental stage, and are being distributed free to selected groups of scientists in return for 'feedback' in the form of information and criticism. The third type of bibliography is tailored to suit the needs of the individual, who defines his sphere of interest by means of a word profile which can be fed into a computer. The computer then produces a list of titles and bibliographical details, which are set in type by GRACE (Graphic Arts Composing Equipment). The system demands little of the research worker; all he has to do is to produce a word profile (some librarians, trained by the National Lending Library, can assist in this) and send it to the NLL, which will send free of charge a bibliography covering research in his area of interest since 1963 .

This open-handedness can scarcely last for ever. The cost of the input end of the system is carried by the Department of Health, Education and Welfare in the United States, while in Britain the running costs of the system are paid by the Science Research Council. When the experimental period ends in 1968, it will have to be decided whether the benefits of the system justify its cost. So far British experience indicates that it is a useful service: one worker said that of the
295 titles selected by the computer 59 were useful to him. To have found these 59 papers without the computer would have meant reading 17,500 references. It also seems that however well read an individual may be, the computer will turn up titles he had not come across before. Whether the costs of the service are justified will only be known when some estimate of its usefulness can be made; British medical research workers are therefore being urged to make use of the service, and then to tell the National Lending Library what they think of it.

\section{Synonyms for Chemists}

Chemists should be less frequently at a loss for words now that the Chemical Abstracts Service of the American Chemical Society has published the word guides which are intended to help those who would extract information from the reels of magnetic tape on which information about the titles of chemical articles in the literature is being stored. The lists now available are more than mere thesauri in the sense of Roget, for the groups of words associated with each main entry in the lists are allocated to categories intended to give some sense of the character of the relationship between words in a pair. Two word guides are available, one for use with the Chemical Titles tapes and one with the magnetic tapes called Chemical-Biological Activities on which are stored the titles of articles in some 600 periodicals and short abstracts as well.

As well as straightforward synonyms for words, the guides include terms which are both broader and narrower, together with some which are merely close relations. For example, the chemist who looks up "Hamster" will find that the terms "Animal" and "Rodents" are both broader terms, that "Chinese Hamster" is a narrower term, that "Rat" is a related term and "Cricetus cricetus" is a synonym. The importance of the word guides stems from the way in which machine retrieval systems require the potential user to specify the area of his curiosity by means of words or word stems. Computers will pick out titles in which the specified words appear, either singly or in combination with others. One obvious difficulty is that of anticipating at the beginning of a search the variants which may be substituted for particular words by different authors. Such is the enthusiasm of the Chemical Abstracts Service for machine retrieval that it is presumably only a matter of time before the word guides themselves are incorporated into the machine programmes. In the meantime, etymologists will be glad to see that the word guides take a stern line on a great many malpractices. Thus those who would use the word "level" instead of "concentration" will get, no encouragement from the first editions, at least.

\section{British Abortion Law}

Mr. Davin Steel's Medical Termination of Pregnancy Bill, 1966, which reached the committee stage of the House of Commons this week, seems assured of getting through the House in one form or another. The Bill is not quite as radical as some of its opponents (and, indeed, some of its supporters) have maintained. It docs, however, extend somewhat the grounds for abortion that are already recognized in case law. It would legalize abortion if, in the opinion of two 